\title{
What can be done to Prevent Accidental Toxic Release, Fire \& Explosion in Chemical Process Industry?
}

\author{
Easir A Khan* \\ Department of Chemical Engineering, Bangladesh University of Engineering and Technology, Bangladesh
}

Submission: March 27, 2017; Published: April 19, 2017

*Corresponding author: Easir A Khan, Assistant Professor, Department of Chemical Engineering, Bangladesh University of Engineering and

Technology, Bangladesh, Email: eakhan@che.buet.ac.bd

\begin{abstract}
Public perceptions are significantly affected by industrial incidents and the contribution and essential societal role of different industries are often overlooked when any catastrophic incident occurs. What can be done to prevent release of toxic chemical, fire \& explosion or any other catastrophic incidents? Majority of the incidents occurred in the process industries due to lack of competence, system failure, human error and/or someone did not do what they were supposed to do. The root causes of the incidents in process industries are more or less same. The incidents can be avoided if the organization maintains a positive safety culture to improve its process safety performance and take advantage of lesson learned from the previous incidents. Everyone in any organization starting from the Chairman and Chief Executive Officer, senior executives, supervisors and operators should be accountable and responsible for their appropriate roles to ensure health and safety performance of the company.
\end{abstract}

Keywords: Bangladesh; Chemical Incidents; PSM Standard; Lesson Learned; Toxic release and Fire \& Explosion

\section{Introduction}

The toxic and hazardous chemicals release, fire \& explosion were pretty frequent which caused multiple fatalities, injuries, significant property and environmental damage [1-3]. The question remains that can the occurrence of these disastrous accidents be reduced in the future and their consequences minimized? An effective implementation of Process Safety Management (PSM) program in the process industries could significantly reduce the risk and avoid catastrophic fires, explosions, releases of hazardous substances and/or minimized its consequences. In United States, process industries are required to meet OSHA PSM standard. OSHA Process Safety Management (PSM) standard has fourteen majors' interrelated elements [4]. Employee Participation, Process Safety Information, Process Hazard Analysis (PHA), Safe Operating Procedures, Training, Contractors, Pre-startup Safety Review, Mechanical Integrity, Hot Work Permit, Management of Change, Incident Investigation, Emergency Planning and Response, Compliance Audits and Trade Secrets. All of these elements are equally important. Among them, process hazard analysis (PHA) is heart of OSHA's Process Safety Management (PSM) standard. Process hazard analysis is a thorough, orderly and systematic approach or technique to identify, assess and control the potential hazard associated in process industries. Process hazard analysis must need be conducted to identify all causes, estimate the risk and develop strategies to address the risk in chemical process industries.

Many of the developing countries (e.g. Bangladesh) do not have the process safety regulations/standards for process industries. There are significant numbers of industries in Bangladesh dealing with toxic, flammable and others hazardous chemical or materials those have potential to cause serious harm to employees, public and the environment. The number of chemical incidents is also increasing in Bangladesh these days. There were three major chemical incidents in 2016 which caused 40 fatalities, significant property and environmental damage. Quite often the accidental release of toxic chemicals, fire and explosion are narrowly defined and include only the ones that caused serious or catastrophic consequences [2].

The government or regulatory authorities should adopt the process safety management standard for process industries if they don't have yet. An effective implementation of process safety management program in the process industries and monitoring the process safety performance are required to avoid any future catastrophe. The process industries should have a good incident investigation procedures necessary to take advantage of the lessons learned. 


\section{Recent Advances in Petrochemical Science}

\section{Major Safety Incidents}

Piper Alpha, a North Sea Oil Production Platform was located approximately 120 miles Northeast of Aberdeen. On 6th July 1988, an explosion occurred on a North Sea oil production platform known as Piper Alpha which killed 167 employees. Total property damage from the explosion was estimated to be approximately $\$ 1.4 \mathrm{bn}$. A safety relief valve for a spare condensate pump was removed and temporarily sealed with a blind flange by the day shift operators. Unaware of the temporary replacement the night shift operators restarted the spare pump and gas condensate leaked from the flanges and ignited. The incident was attributed mainly to human error and an eye opener for the offshore industries regarding the safety issues. Inadequate maintenance and safety procedures, lack of communication between shift, faulty design and improper emergency response and planning led to the catastrophe [1,3]. After Piper Alpha, safety policies and regulations were developed and implemented in United Kingdom.

The incidents of Flixborough (1974), Seveso (1976) and Bhopal (1984) showed the world its catastrophic potential of process industry that can cause harm to people and environment [1]. Bhopal tragedy became the worst ever industrial accident in the history. On 3rd December 198440 ton of highly toxic methyl isocyanate (MIC) was released due to runway reaction in MIC storage tank. Water was accidentally entered into the MIC storage tank and reacted with MIC exothermally. This caused runway reaction and produced excessive heat inside the tank. Consequently, MIC was vaporized and released to the atmosphere. The toxic exposure immediately killed over 2000 people of Bhopal due to respiratory distress [4] and caused a significant increase of morbidity and thousands of premature deaths in the subsequent years. The fundamental causes of the incident were inadequate reactive hazard assessment, faulty instruments and ineffective release management system [5].

\section{Process Safety Management and Legislation}

Bhopal incident was the wake-up call for the Indian government. After the disaster, environmental policies and regulation enacted including the Air Act (1987), the Hazardous Waste (Management and Handling) Rules and the Environment Protection (2nd Amendment) Rules 1992. The Bhopal incident received widespread media attention and changed world view on the importance of process safety issues. U. S Unions begin to lobby for a Process Safety Standard. By investigating the underline causes of major industrial incidents, OSHA proposed a process safety management (PSM) standard for highly hazardous chemicals in 1990. After an extensive public hearing and debate, PSM standard was effective in 1992 aiming to prevent accidental release of chemicals that could pose a threat to employees or the environment. Seveso incident was main driver to develop process safety regulations for European Union. EU process safety management and legislations were introduced as Seveso |
I Directive (1982), Seveso II Directive (1996), later modified in 2003 and Seveso III Directive (2012).

\section{Case Study: Effect of Deficiencies in Process Safety Management Program}

Let's look at the case of a recent incident at Williams Geismar Olifins Plant, Geismar, Louisiana. A reboiler (shell \& tube heat exchanger) that supplied heat to distillation column was catastrophically ruptured on 13th June 2013, causing a boiling liquid expanding vapor explosion and fire. The incident killed two operators and injured 167 individuals [6]. What went wrong? In original design, two reboilers were continuously in operation to feed the distillation unit. However, it requires shutdown of the distillation unit for periodic maintenance and cleaning due to fouling on the tube surface of the reboiler. For reduction of process downtime, Willium decided to change the process and installed new valves and piping in 2001 so that it allows one reboiler at a time and the other can be kept standby or ready to use. These changes introduced a new process hazard as the additional valves isolated the reboiler from its relief valves that located on the top of the distillation column.

On the day of the incident, Willium operators noticed the flow rate of hot water in functioning reboiler was decreasing last couple of days. It could be because of fouling. So operators decided to switch the standby reboiler online. Unknown to the operators the reboiler shell side process valve was closed and blocked-in with partially filled liquid propane due to valve leaking or inadvertent opening of a valve. When reboiler hot water valves were opened, liquid propane inside the shell begun to heat up. Due to thermal expansion of liquid propane, a dramatic pressure rise within the shell caused boiling liquid vapor explosion and fire. Process safety management program weaknesses at Willium facility during 12 years led to the reboiler to be unprotected from overpressure. These weaknesses include deficiencies in implementing Management of Change (MOC), Pre-Startup Safety Review (PSSR) and Process Hazard Analysis (PHA). Chemical Safety Board investigated the incident and identified a number of process safety management program deficiencies that contribute to the incidents which includes

A. Willium didn't perform adequate Management of Change,

B. Willium did perform three process hazard analysis during 2001 to 2013, but they didn't implement the action items from PHAs or recommendation from a contracted pressure relief system engineering analysis

C. Willium didn't assess the hazard before the start up of standby reboiler which was a crucial mistake. The incident of Willium facility could be avoided if they performed MOC appropriately, assessed the overpressure hazard and/or implemented the recommendation of PHAs. One of key lesson from the incident is that overpressure protection is 
essential for all pressure vessels and PHA team must need to ensure the effective overpressure protection system for all the pressure vessels in process industry.

\section{Conclusion}

Despite all the rules and regulations, chemical accidents are still happening. The analysis of the past catastrophic incident clearly indicates the lack of scientific and technical competencies as well as deficiencies in managing safety issues. Therefore, a three-way partnership is required from academia, industry and the government. Academics from the universities/ research/training institutions should recognize the importance of process safety to improve the technical competency level for both practicing engineers and new graduates. The process safety education should be integrated into the engineering curriculum. The government regulatory authority should set a minimum safety program requirements or standards for process industries. The process industries should implement various programs aiming to improve process safety management performance and develop a good safety culture.

\section{References}

1. Mannan MS (2005) Lees' Loss Prevention in the Process Industries. ( $3^{\text {rd }}$ edn), Amsterdam: Elsevier, Netherlands, ISBN: 9780080489339.

2. Khan EA (2016) Dap-1 Ammonia Tank Explosion: Safety and Security Concerns in Chemical Process Plant in Bangladesh. Int J Petrochem Sci Eng 1(1).

3. Mannan MS, Reyes-Valdes O, Jain P, Tamim N, Ahammad M, et al. (2016) The evolution of process safety: current status and future direction Annu Rev Chem Biomol Eng 7: 135-162.

4. Crowl DA, Louvar JF (2002) Chemical Process Safety: Fundamental with Applications, $\left(2^{\text {nd }}\right.$ edn). Prentice Hall Inc, USA.

5. Mannan MS, West H, Krishna k, Aldeeb A, Keren N, et al. (2005) The legacy of Bhopal: The impact over the last 20 years and future direction. Journal of Loss Prevention in the Process Industries 18(4-6): 218-224.

6. (2016) Willium Geismar Olyfins Plant: Boiler Rapture and Fire, Chemical Safety and Hazard Investigation Board (CSB) Case Study, Geismar, LA, USA.

Your next submission with Juniper Publishers will reach you the below assets

- Quality Editorial service

- Swift Peer Review

- Reprints availability

- E-prints Service

- Manuscript Podcast for convenient understanding

- Global attainment for your research

- Manuscript accessibility in different formats

( Pdf, E-pub, Full Text, Audio)

- Unceasing customer service

Track the below URL for one-step submission https://juniperpublishers.com/online-submission.php 